\title{
Synthesis of Pro Drug Polyester and Control Release
}

\author{
Abeer Abd Alrazaak M. \\ Department of Chemistry, College of Science AL-Mustansiriyah University, Baghdad-Iraq. \\ E-mail: Abeerabd16@yahoo.com
}

\begin{abstract}
Lactic acid was used as difunctional spacer could reacted with glycerol gave its corresponding ester derivative with remain the hydroxyl groups of lactate units which reacted with carboxyl group of Mefenamic acid forming ester attachment, the prepared pro drug have many development, it could enhanced the drug with easier hydrolysis through ester-ester groups with extended the arm pendant substituted drug. The action of polymeric drugs depends on hydrolytic and cleavage of the drug moiety from the polymer, this give advantages of late and sustained release of drug over long time with decrease of side effects, the modification percentage test was carried out, also it was characterized by FTIR and ${ }^{1} \mathrm{H}-\mathrm{NMR}$ spectroscopes. Controlled drug release was deliberate by using different $\mathrm{pH}$ values at $37^{\circ} \mathrm{C}$. Thermal stability of the drug polymer was observed, indicated the protection of drug with longer expire date. [DOI: 10.22401/JNUS.20.1.01]
\end{abstract}

Keywords: Glycerol, Lactic acid, Mefenamic acid.

\section{Introduction}

Some investigators have focused their attention on the preparation of bioactive polymeric materials, by bounding the drug to a polymer through covalent linking. A polymer based on a C-C backbone can resist degradation, whereas (1) it can be hydrolysis such as anhydride ester or amide bonds. The degradation is resulting in a scission of the polymer backbone (2). In order to be used in medical devices and controlled-drug-release applications, the drug polymer must be biocompatible and to be qualified as biomaterial- process and capable of controlled stability (3). Poly(esters) based on poly lactide (PL), poly glycolide (PGA), and their copolymers was used as biomaterials $(4,5)$, Other bio- and degradable polymers include, poly(ester)s, It was used as natural polymers, particularly, modified poly(saccharide)s (4) was investigated for usability in a specific lactic acid production process based on bipolar electro dialysis/ Lactic acid has become an essential additive for flavor and preservation in a large number of industries including food manufacturing (5) its applications such as drug delivery to the production of pro drug (6), Because of this increasing demand, and also because of the more and more severe environmental constraints, more efficient lactic acid processes lead to less by-products are needed (7). The commercially used as a nano filtration membrane and by electro dialysis (first potential integration level)(8), two molecules of lactic acid can be dehydrated to form lactide. In the presence of catalysts, lactide polymerize to either atactic or syndiotactic polylactide (PLA), which used as biodegradable polyesters. PLA is also employed in pharmaceutical technology to produce water-soluble lactates it further use in topical preparations and make up to regulate acidity and for its disinfectant and keratolytic properties (9). Lactic acid is found in milk laban, yogurt, kefir (10). Carbohydrate includes everything other than water, protine, fat, ashand ethanol (11) This means a value of 4 calories per.

Will be used for any lactic acid in calculating the food energy. Sugars into acids, unlike yeast, who ferment sugar into ethanol (12). In winemaking, a bacterial process, natural or controlled, is often used to convert the naturally present malic acid to lactic acid, Lactic acid is an organic compound with the formula $\mathrm{CH}_{3} \mathrm{CH}(\mathrm{OH}) \mathrm{CO}_{2} \mathrm{H}$. It is a white, water-soluble solid or clear liquid that is produced both naturally and synthetically with a hydroxyl group, This higher acidity is the consequence of the intra molecular hydrogen bonding between the $\alpha$-hydroxyl and the carboxylate group (13). In medicine, lactate is one of the main components of la-cted Ringers solution and Hartmanns solution is repeatedly shaped even at rest and during reasonable exercise (14). The production of $\mathrm{H}^{+}$has the 
same charge: "Lactate-production is not associated with a stoichiometrically equivalent of protons $(\mathrm{H}+)^{\prime \prime}(15)$. It is pyruvate production from neutral glucose that generates (16-23) and enhancing brain aerobic energy metabolism in vitro (24-25) ests for lactate are performed to determine the status of the acid base homeostasis in the body for this purpose is often by arterial blood sampling (26-27).

Mefenamic acid (MF), N-(2,3-Xylyl) anthranilic acid, is a non-steroidal drug. It has analgesic and antipyretic properties. Antiinflammatory drug (30). The side effects include: headache, nervousness, vomiting, diarrhea, hematemesis (blood urine), and skin rash and swelling.

\section{Experimental}

\section{Materials and Instruments:-}

Mefenamic acid was purchased from Samurra Company; Thionyl chloride and Triethylamine were obtained from Fluka. Lactic acid and Glycerol were obtained from Aldric. Dimethylformamide was purchased from Me -rck. ${ }^{1} \mathrm{H}-\mathrm{NMR}$ spectra were recorded on a Sh-imatzu spectrophotometer in dimethyl sulph-oxide (DMSO). The FTIR spectra were recor-ded by $\left(4000-400 \mathrm{~cm}^{-1)}\right.$ on a Shimatzu spect-rophotometer. Melting points were determin-ed on callenkamp MF B-600 Melting point-apparatus. Thermal analyses were performed using TGA and DTG in Ibn Sina Center, Ba-gdad, Iraq. Electronic spectra measurement using CINTRA5-UV-Visible.

\section{Preparation of Mefenamic acyl Chloride A1(24-25)}

A thionyl chloride $(5 \mathrm{ml}, 0.04 \mathrm{~mole})$ was added gradually to a mixture (2. 48g., 0.04 mole) Mefenamic acid which was dissolved in $15 \mathrm{ml}$ of dioxane, placed in a round-bottom flask provided with condenser, the contents were stirred with a magnetic bar at room temperature. The excess of thionyl chloride was distilled off and the product was isolated and dried. Producing white powder, it was collected on a glass filter, washed repeatedly with ether giving 90\%. It was immediately used in the following procedure of preparation of $\mathrm{A} 3$, because it is very reactive.

\section{Esterification of Glycerol with lactic acid}

A2 (26):- In a round bottom flask provided with condenser (14g., 0. 041 mole) of Glycerol was added to (15g., 0. 124mole) of Lactic acid the mixture was refluxed with stirring for $2 \mathrm{hrs}$, the viscous product was obtained, washed with ether and dried at room temperature. The polymer was obtained with. $89 \%$ as a colorless viscous polymer with $\mu_{\mathrm{in}}=0.76 \mathrm{dL} / \mathrm{g}$.

\section{Substitution of Polymer A2 with M Mefenamic acid chloride A1 to \\ A3 polymer (26) \\ (2g., 0.013 mole) of prepared polymer A2,} was dissolved in of dioxane: DMF mixture $(5: 1 \mathrm{vol}$.$) , the mixture was heated at 60^{\circ} \mathrm{C}$ the prepared acyl chloride and $(1 \mathrm{ml})$ of triethylamine was added to dissolved (4. 5g., 0. 013mole) Mefenamic acyl chloride A1, the mixture was refluxed with stirring for $3 \mathrm{hrs.}$, The solvent was evaporated under vacuum; the product was washed with water three times, dried under vacuum oven. The yellow polymer was obtained with conversion percentage $72 \%$. The softening point of the drug polymer was $(180-190){ }^{\circ} \mathrm{C} . \mu_{\text {in }}=0.81 \mathrm{dL} / \mathrm{g}$.

\section{Determination of degree of acid substitution (Conversion Percentage). (26)}

$(5 \mathrm{mg})$ of prepared drug polymer was dissolved in $2 \mathrm{ml}$ of $0.1 \mathrm{~N} \mathrm{NaOH}$, the solution was heated to $70^{\circ} \mathrm{C}$, for $10 \mathrm{~min}$ in a water bath, cooled and the resulting solution was titrated with $0.1 \mathrm{~N}$ HCL to determine the excess of $\mathrm{NaOH}$ solution which equivalent to unreached of mefenamic acide.

\section{Controlled drug release (27):-}

(100mg.) of dried prepared drug polymer was poured in $(100 \mathrm{ml})$ of aqueous buffer solution such as (phosphate buffer $\mathrm{pH}$ 7. 4) or acidic (solution $\mathrm{pH} 1.1$ ). The buffer solution maintained at $37^{\circ} \mathrm{C}$. With stirred and $(3 \mathrm{ml})$ of sample was analyzed by UV spectrophotometer, it was compared with mole fraction curve which was obtained computerized under similar medium. Fig. (4), showed controlled drug release in different $\mathrm{pH}$ values at $37^{\circ} \mathrm{C}$. 


\section{Results and discussion:-}

The main objective of the research is to synthesis and study of lactate polymers containing drug substituted groups. The work includes ester attachment.

The action of polymeric drugs depends on hydrolytic on cleavage of the drug moiety from the polymer this give advantage of delayed and sustained release of drug over time with corresponding decrease of side effect.

\section{Glycerol was reacted with Lactic acid produced ester polymerA2as shown below:}<smiles>CC(O[GaH][18OH])C(=O)O</smiles>

The prepared polymer $\mathrm{A}_{2}$ was characterized by FTIR spectrum, Fig (1) shows the band assigned to the terminated $-\mathrm{OH}$ of lactic acid at $3392 \mathrm{~cm}^{-1}$ due to the hydroxyl group of substituted lactic acid group, and $2974 \mathrm{~cm}^{-1}$ of C-H aliphatic, $2785 \mathrm{~cm}^{-1}$ of methyl, $1718 \mathrm{~cm}^{-1}$ represented to(ester carbonyl) and $1126 \mathrm{~cm}^{-1}$ of $\mathrm{C}-\mathrm{O}$ ester.

Fig (3) ${ }^{1} \mathrm{H}-\mathrm{NMR}$ spectrum of $\mathrm{A}_{2}$ showed the signals at $2 \mathrm{CH}_{2}-\mathrm{CO}(2 \mathrm{H}) \mathrm{d}, \delta: 2.8 \mathrm{ppm}$ of $\mathrm{CH}-\mathrm{CO}(1 \mathrm{H})$ and $\delta: 2.4 \mathrm{ppm}$ of $\mathrm{CH}-\mathrm{CO}$ $(1 \mathrm{H}) \mathrm{S}$., and $\delta: 1.3 \mathrm{ppm}$ due to $\mathrm{CH}_{3}$ terminal of $(3 \mathrm{H}) \mathrm{d}$, of Lactic acid, $\delta: 4.0 \mathrm{ppm}$ of $\mathrm{O}-\mathrm{CH}(1 \mathrm{H}) \mathrm{Q}$, and The remained carboxylic acid and Lactic acid. FTIR spectrum Fig (2) ester polymer $\mathrm{A}_{3}$ showed the beak at and $3063 \mathrm{~cm}^{-1}$ of $\mathrm{C}-\mathrm{H}$ aromatic, $1705 \mathrm{~cm}^{-1}$ is attributed to (carbonyl-ester) and the other absorption appeared at $1722 \mathrm{~cm}^{-1}$ is for carbonyl of acid and the new absorptions were appeared at $3417 \mathrm{~cm}^{-1}$ of $\mathrm{NH}$ amine of drug.

The thermal stability of prepared polymer was investigated by thermo-gravimetric analysis (TGA) and (DSC). This technique is based on measuring the weight loss as a function of time at constant temperature or as Fig.(4) a function of temperature at constant rate of heating. In the present study, the thermal stability of the prepared polymer was tested by thermo-gravimetric technique by measuring the sample weight change at a

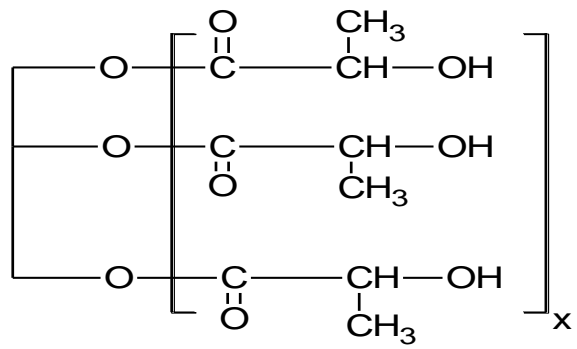

programmed rate of heating. The change in weight was measured as a function of temperature which gave valuable information about the thermal stability of the prepared compounds. Prepared polymer was taken from under a programmed heating rate of $20^{\circ} \mathrm{C} /$ min. (use Helium as inert gas in rat $20 \mathrm{ml} / \mathrm{min}$ ). Thus the weight-loss vs. temperature thermograms were recorded and analyzed. as shown in Table (1), which indicated the good thermal resistance and showed three steps of weight loss-temperature. This high thermal resistance indicated the high molecular weight of the prepared polymers with high interaction between hydrogen bonding through the polymer chain.

Table (1)

Thermal stability parameter of prepared polymerA3.

\begin{tabular}{|c||c||c||}
\hline Codes No. & Temp. ${ }^{\mathbf{C}}$ C & $\begin{array}{c}\text { Weight } \\
\text { Loss\% }\end{array}$ \\
\hline \multirow{3}{*}{ Polyester A3 } & 15.81 & 4.2791 \\
& 122.66 & 91.3488 \\
& 199 & 90 \\
\hline
\end{tabular}

Fig (5) showed the release profile of drug release (mole fraction) versus time.

The controlled release rates was studied as drug polymers which could be hydrolyzed in 
basic and acidic medium due to ester-ester bonds.

In this work it was concluded that the presence of difunctional spacer group was inserted between the drug and polymer backbone through ester group which could easy hydrolysis as a pendant group, with increasing of satiric effect of polymer chains., that the extended side arm of Glycerol with suitable spacer di-functional such as Lactic acid (26) with Mefenamic acid as a drug. In basic medium, the rate of hydrolysis is higher than acidic medium this is due to the presence of $\mathrm{OH}^{-}$in alkaline, which acts as a good nucleophilic attack to $\mathrm{H}^{+}$bonded to oxygen atom of ester as shown in Scheme (2). The spacer effect appeared carbonyl grop with respect to water, and the $\mathrm{H}_{2} \mathrm{O}$ is faster.

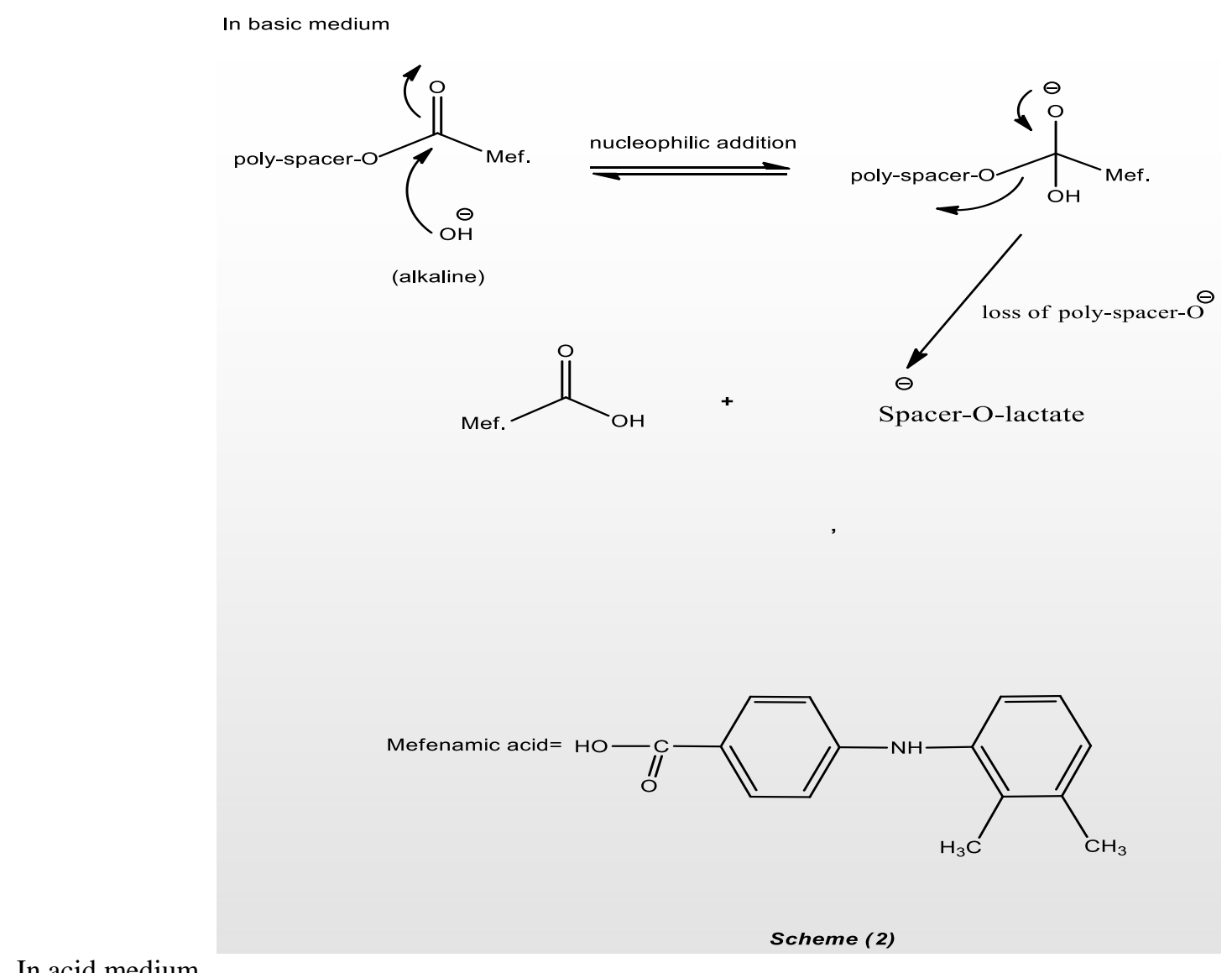

Scheme (2) 


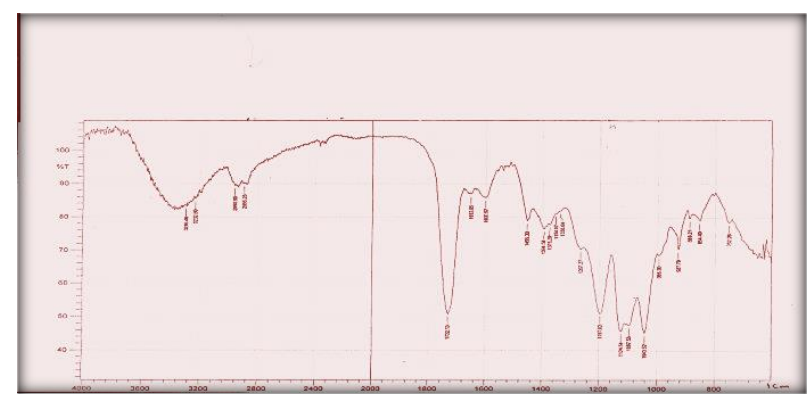

Fig.(1): FTIR spectrum of A2.

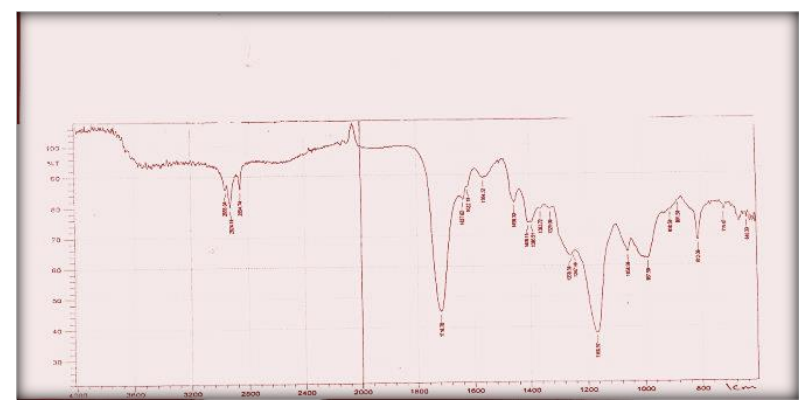

Fig.(2): FTIR spectrum of (A3)

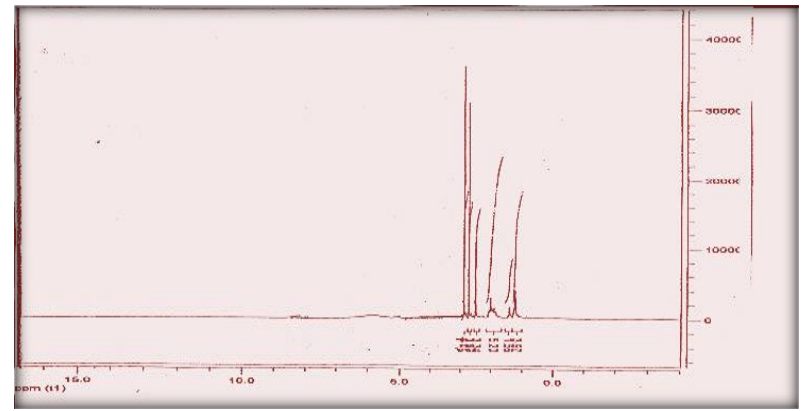

Fig.(3): HNMR.

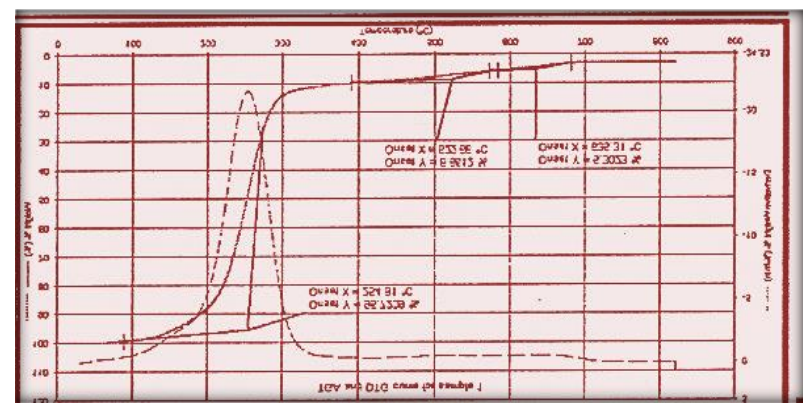

Fig.(4): TGA of A3.

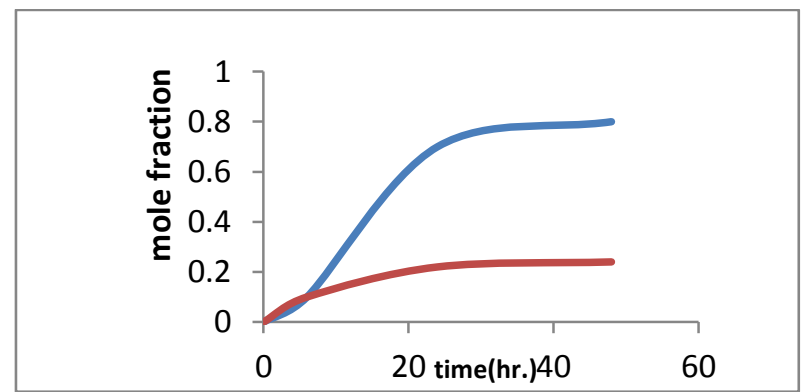

Fig.(5:) Drug release of $A 3$ at $p H ~ 1.1$ and 7.4 at $37 \mathrm{C}^{\circ}$ at $400 \mathrm{~nm}$.

\section{References}

[1] Ottenbrite R.M. and Dunn R.L., (Polymeric drugs and drug delivery systems “ACS Sympoisum Series 469"), American Chemical Society, Washington, D.C., P.3, 1991.

[2] Vogl O., and Donaruma L. G., Polymeric Drugs, Academic Press, New York, NY, 1978.

[3] Li Y.Q., and You H.B., (Polymer architecture and drug delivery), Pharmaceutical Research, Vol. 23, No. 1, January, 2006.

[4] Zhang, X.et al. J. M. S.-Rev. macromol. Chem. Phys., C33 (1), 81, 1993.

[5] Good, ML; Harris, JE; Hemandez, A; Gladden, LB. "Blood lactate measurement and analysis during exercise:a guide for clinicians." Journal of diabetes science and technology1 (4):558-69., July 2007.

[6] Badef, C; Thebaud, NB. "Ecology of lactobac-illi in the Oral Cavity: A Review of Literature". The open microbiology journal 2:38-48., 2008.

[7] Ascimento, MM; Gordan, VV; Garvan, CW; Browngardt, CM; Bume, RA). "Correlations of oral bacterial and urea catabolism with caries experience". Oral microbiology and immunology 24(2):8995, 2009.

[8] Aas, JA; Griffen, Al; Dardis, SR; Lee, AM; Olsen, I; Dewhirst, FE; Leys, EJ; Paster, BJ, "Bacteria of Dental Caries in Primary and Permanent Teeth in children and Young Adults". Journal of clinical microbiology 46(4):1407-17., 2008.

[9] Caufield, PW; Li, Y; Dasanayake, A; Saxena, D "Diversity of Lactobacilli in the Oral Cavities of Young Adults Women with Dental Caries". Caries Res.41(1):2-8., 2007.

[10] Roth, Stephen M. "Why does lactic acid build up in muscles? And why does it cause soreness?" Retrieved 23 January, 2000.

[11] McArdle, W.D., Katch, F, I., \& Katch, V.L., 2010. Exercise physiology Energy, nutrition, and human performance. Wolters Kluwer/Lippino-Cotto William \& Wilkins Kluwer/Lippinocott Williams \& Wilkins Health.

[12] McArdle, W.D., Katch, 2010. Exercise physiology: Energy, Nutrition, and Human 
Performance. Wolters Kluwer/Lippinocott Williams \& Wilkins Health.

[13] Wyss MT, Jolivet R, Buck A, Magistretti PJ, Weber B "In evidence for lactate as a neuronal energy" Neurosci.31 (20):747785. .PMID21593331, May, 2011.

[14] Gladden LB "Lactate metabolism: a new paradigm for the third millennium". J. Physiol (Lond.) 5585-oi: 10.1113/ physiol. 2003. 058701. doi:10.1113/physiol. 2003. 058701. PMC1664920 PMID15131240, July 2004.

[15] Tyzio R, Allene C, Nardou R, et al. "Depolarizing actions GABA in immature neurons depend neither on keton bodies nor on pyruvate". J. Neurosci. 30(46):1563842, November 2010.

[16] Ruusuvuori E, Kirilkin I, Pandya N, Kaila K "Spontaneous network events driven by depolarizing GABA action in neonatal hippocampal slices are not attributable to deficient mitochondrial energy metabolism. J. Neurosci”. 30(46): 15638-42, Novomber, 2010.

[17] Khakhlin AS "Questioning the depolarizing effects of GABA during early brain development" Neurophysiol 106(3):1065-7. doi: 10.1152/ jn. 00293. 2011. PMID21593390, May, 2011.

[18] Firyal M.A., Abeer A.M, Sharooq S.K., and Wassal M.Kh., (sulfonation and substitution of poly vinyl alcohol with amino antibiotics), J. Babylon university, No.1 Vol.22, P.401-407, 2012.

[19] Firyal M.A., Taghreed H. and Saif M.A., Synthesis and characterization of Gelatin-gpoly acrylamide proflavine and controlled release study, Chemical and Process Engineering Research Journal, 32, 53-61, 2015.

[20] Firyal M.A. and Saif M.A., Synthesis and characterization of new (N-ethyyl acrylic Amide Mefenamaten polymer, J. of Babylon University, 23(5), 2014.

[21] Taghreed H., Firyal M. and Saif M., Synthesis of drug carrier poly acrylic acid with spacer group, International J. of Technical Research and Applications Vol.3, Issu 3, P.300-306, 2015.

[22] Firyal M., Taghreed H., Saif M., Lactic acid as spacer between poly acrylic acid

and 4-AminoantipyrineJ. of Sport Research, 2016.

[23] Firyal M. and Sanaa H., Casein grafted maleic anhydride copolymer and substituted with procaine, J. Natural SCI. Rrsearch, 2015.

[24] Firyal M., Sana H. and Mena M., Synthesis of substituted gelatin grafted maleic anhydride as drug copolymer, Chemical and Materials Research Vol.7, No.5, P.1-8, 2015.

[25] Firyal M., Firas A. and Ahmed Y., Synthesis of prodrug ciprofloxacine procaine male amide, Polymer Iraq National Journal of Chemistry (NJC), Vol.56, P.416-425, 2014.

[26] Firyal M. and Siaf M., Synthesis and characterization of new (N-ethyl acrylamide mefenamate), J. of Babylon University Vol.23, No.5, 2015.

[27] Firyal M., Firas A. and Ahmed Y., Synthesis of ciprofloxacin prodrug chitosan, J. of Babylon University, Vol. 23, No.7, 2015.

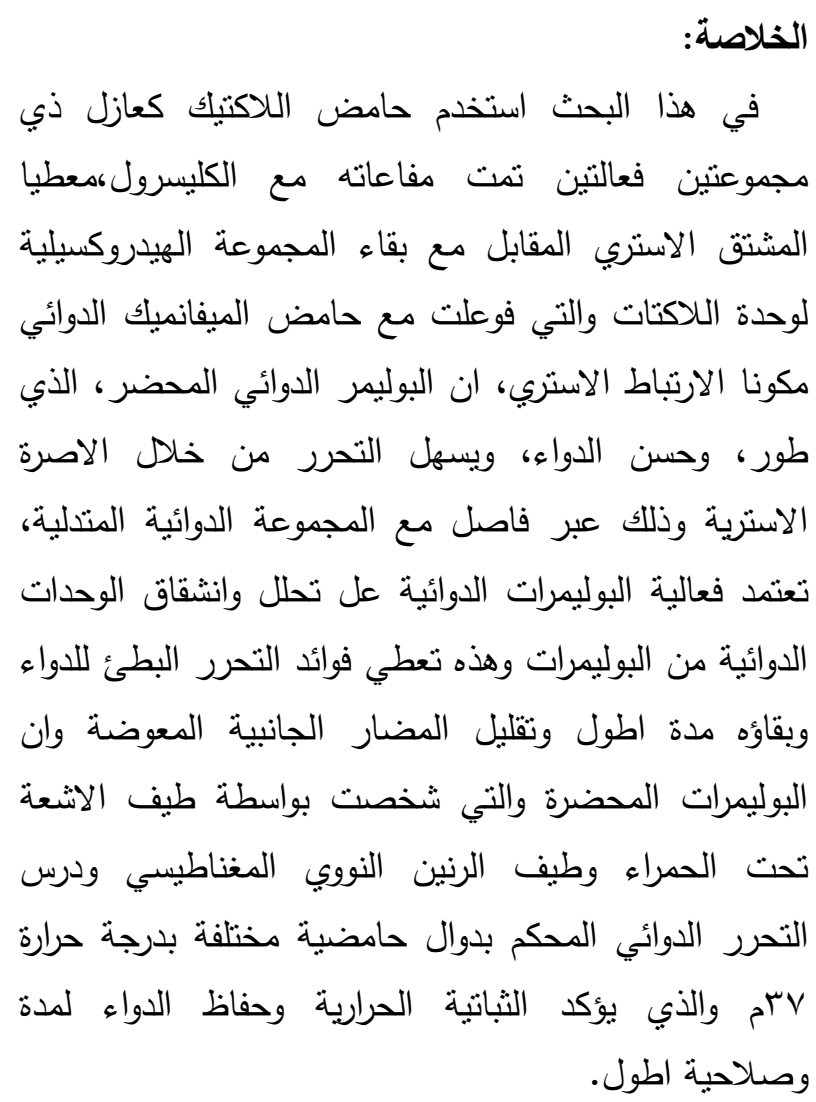

